\title{
The Tetrapharmakos (Fourfold Cure) and the Sober Reasoning in Epicurus: A Critical Philosophical Paradigm against the Politicization of Medical Truth?
}

\author{
Anna Ch. Markopoulou ${ }^{1}$
}

\begin{abstract}
In the present paper, we will discuss how the therapeutic effect of Epicurean philosophy as a pharmakon for human passions constitutes a critical philosophical paradigm against the politicization of medical truth. More specifically, we will argue that the concept of correcting habits of thought, which confers a philosophical meaning on the Greek word pharmakon, constructs a dialectical relationship of unity between nature and man. Then we will show that this conception is in contrast to the traditional meaning of pharmakon as an artificial means of therapy, which is ideologicalised in the politicization of medical truth, since it presupposes a technocratic conception leading to a dualism between superior technology, which rules, and inferior human nature, which is ruled. We will argue that establishing an enhancement of human nature as it ensues from the Epicurean ethics of the tetrapharmakos constitutes a critical philosophical paradigm against the politicization of medical truth.
\end{abstract}

Keywords: Epicurus; Pharmakon; Sober reasoning; Politicization; Medical truth

\section{The twofold meaning of Pharmakon}

The aim of this paper is to show how the therapeutic effect of the Epicurean philosophy as a pharmakon for human passions constitutes a critical philosophical paradigm against the politicization of medical truth. More specifically, we will discuss how the concept of correcting habits of thought, which assigns a philosophical meaning to the Greek word pharmakon, creates a dialectical relationship of unity between nature and human. By contrast, the traditional meaning of pharmakon as an artificial means of therapy is ideologicalised in the politicization of medical truth, since it presupposes a technocratic conception leading to a dualism between the superior technology, which rules, and the inferior human nature, which is ruled. From this point of view, we could argue that the pharmakon keeps its harmony with nature because the philosopher has assumed a stance of autonomy in self-reflection, whereas the subject of the state has abdicated the responsibility of autonomy.

The etymology of the Greek word pharmakon is twofold: it originates from the verb $\varphi \varepsilon \in \varrho$ and

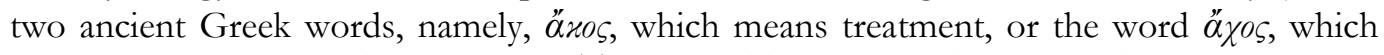
means poison (Gaisford, 19672, 146). This twofold etymology highlights the coexistence of two opposing meanings in the same word, which, in turn, assigns this word a truly dialectical

\footnotetext{
${ }^{1}$ Anna Markopoulou, Ph.D. in Science Education, University of Sorbonne (Paris V René Descartes).
}

E-mail: ann2mark@otenet.gr. 
function. In this sense, pharmakon is simultaneously the poison and the means of purification, as well as the consequent treatment of the disease caused by the poison. In the same vein, Jacques Derrida underlines the twofold meaning, and the related dialectical function of pharmakon. In relation to that point, he states:

The eidos, truth, law, the episteme, dialectics, philosophy—all these are other names for that pharmakon that must be opposed to the pharmakon of the Sophists and to the bewitching fear of death It is pharmakeus against pharmakeus, pharmakon against pharmakon (Derrida, 1981, 124).

It is this twofold meaning of pharmakon that is also observed in the Tetrapharmakos of Epicurus, who proposes four pharmaka to treat four primordial fears that inflict pain on the human soul. In this context, the Tetrapharmakos constitutes a critical philosophical paradigm against the politicization of medical truth to the extent that it highlights the correction of the mind as a philosophical pharmakon by means of which a dialectical relationship of unity is constructed between nature and human. At the same time, it transcends the traditional concept of pharmakon as an artificial means of treatment and, more generally, the medical approach to the improvement of human nature through technology alone. As was mentioned above, this concept is ideologicalised in the politicization of medical truth since it presupposes a technocratic conception leading to a dualism between superior technology, which rules, and inferior human nature, which is ruled. From this point of view, Martha Nussbaum shows the inextricable relationship between the Epicurean epistemology and ethics, and states accordingly that Epicurus' account of the ethical end is inseparable from his general epistemology, according to which the senses are themselves entirely reliable, and all error comes from belief (Nussbaum, 1994, 108).

\section{Tetrapharmakos and its therapeutic action: Towards a correction of the epistemological criterion of truth?}

In this context, we will analyse how Epicurus' Tetrapharmakos, which is the basis of his ethics, is inextricably linked with the four criteria of truth, that is, with his epistemology. In particular, we will examine how each of Epicurus' ethical-philosophical pharmaka is activated and acts therapeutically by correcting the corresponding epistemological criteria of truth that mistakenly lead to irrational fears. The first four aphorisms, which are known as Tetrapharmakos, are presented briefly in his work Principal Doctrines and constitute the main principles of his ethics. They are systematically analysed in the work we will consider here, namely in his Letter to Menoeceus. The first aphorism of the Tetrapharmakos is intended for the treatment of people's fear of the gods (Epicurus, Letter to Menoeceus, 123). The cause of this fear is the false judgements people form about the gods, which, in turn, originate from a fallacy of the senses. In that sense, the first pharmakon aims at treating fear through correcting this fallacy of the senses. Based on Epicurus' Canon, the senses constitute the first of the four criteria of truth (Diogenes Laertius, The Life of Epicurus, 31). The fallacy of the senses derives from the fact that people do not preserve intact their original representations of the gods, but rather endow them with their own human characteristics. It is here that lies the fallacy of the anthropomorphism of the gods, together with the fact that people attribute to the gods the causes of either the greatest harm inflicted on them or the greatest benefit they enjoy (Epicurus, Letter to Menoeceus, 124). 
The second aphorism of the Tetrapharmakos is intended for the treatment of people's fear of death (Epicurus, Letter to Menoeceus, 124). The cause of this fear is the false judgements people form about the pain that imminent death will inflict on them, which, in turn, originate from the fallacy of the passions. In this sense, the second pharmakon aims at treating fear by correcting the fallacy of the passions. Based on Epicurus' Canon, the passions constitute the second of the four criteria of truth, and, according to Diogenes Laertius, they are divided into two types: a) the first one is pleasure, that is, enjoyment, which, because it is inherently familiar to us, constitutes a criterion for those choices that relate to our preferences; and b) the second one is pain, which, because it is inherently alien to our nature, constitutes a criterion for those choices that relate to our avoidances (Diogenes Laertius, The Life of Epicurus, 34). In this context, the fallacy of the passions is twofold: people both fear and avoid death, precisely because they avoid the pain that they mistakenly think will be caused by death. On the other hand, they have a deep yearning for immortality and prefer it to death precisely because they prefer pleasure, which is the enjoyment that they mistakenly think will be brought by immortality (Epicurus, Letter to Menoeceus, 124-125).

The third aphorism of the Tetrapharmakos is intended for the treatment of the fear of the unobtainability of goods (Epicurus, Letter to Menoeceus, 127-128). The cause of this fear is false assumptions, that is, the false judgements that people form about the pain caused by the lack of goods they long for and consider indispensable, which, in turn, leads to the fallacy of preconceptions - prolepsis. In this sense, the third pharmakon aims at treating fear by restoring the fallacy of preconceptions-prolepsis. Following Epicurus' Canon, preconceptions-prolepsis constitute the third of the four criteria of truth and, according to Diogenes Laertius, they relate to the pre-established perception of a thing based on which true judgement is formed (Diogenes Laertius: The Life of Epicurus, 33). Based on Diogenes Laertius, a prerequisite for the formation of preconceptions - prolepsis is memory, that is recalling an external object that has been viewed on numerous occasions, so that what is stored in our minds is either the apprehension of the object or a true belief or a concept or a general idea about things in the external world (Diogenes Laertius, The Life of Epicurus, 33).

Since people's fear of the unobtainability of goods derives, as we have already seen, from the pain they mistakenly believe will be caused by the lack of goods they consider essential for their lives, Epicurus proceeds to a distinction of desires, which constitutes the stable criterion, that is, the measure based on which people will be able to achieve an unwavering comprehension of all of their desires (Epicurus, Letter to Menoeceus, 124-125). In this context, Epicurus initially divides desires into two main categories: vain desires and natural desires. Vain desires concern the desires for unnecessary goods, the acquisition of which, on many occasions, is incompatible with the objective capabilities of the person pursuing them (Epicurus, Letter to Menoeceus, 127).

Epicurus also divides natural desires into those that are merely natural but not necessary for survival, such as, for instance, the excessive pursuit of bodily pleasures, and those that are not only natural but also necessary for life (Epicurus, Letter to Menoeceus, 127-128). This prioritisation of necessary desires is very important since it releases people from the pain caused by the deprivation of goods, thus leading them to the pursuit of happiness, that is, a blissful life, relying on true judgment as their main criterion. 
Furthermore, Epicurus divides necessary desires into three sub-categories:

a. those that are essential for people's survival and, in this sense, necessary for life.

b. those that are needed to ensure the absence of bodily discomfort, that is, the wellbeing of the body, and, in this sense, are necessary for living a good life. In other words, they are essential for the health of the body, which enhances the quality of life.

And

c. those that are necessary for happiness, which results from a combination of body health and ataraxia (inner tranquillity or imperturbability) of the soul. In this sense, they are necessary for living well, that is, for transforming a quality life into a life of blissfulness (Epicurus, Letter to Menoeceus, 127-128).

The fourth aphorism of the Tetrapharmakos is intended for the treatment of people's fear of intolerable evil, that is, the fear that they will not be able to endure evil (Epicurus, Letter to Menoeceus, 129). The cause of this fear is false assumptions, which are the false judgements people form about the pain that will be caused by the number of evils that they imagine will befall them and which they will not be able to endure. These false assumptions, in turn, lead to the fallacy of the imaginary apprehensions of the mind. In this sense, the fourth pharmakon aims at treating fear by restoring the fallacy of the imagined apprehensions of the mind, that is, of the attachment of the mind to mental representations. According to Diogenes Laertius, the imagined apprehensions of the mind, that is the attachment of the mind to mental representations, is the fourth of the four criteria of truth (Diogenes Laertius, The Life of Epicurus, 31).

Error and fallacy originate from the representation formed by adding personal views, which affect the correctness of this representation through the attachment of either the mind or the sensory organs. This fallacy is corrected when the mind is attached to the mental representation of katastematic pleasure, which refers to complete balance and the ensuing ataraxia (inner tranquillity or imperturbability) of the soul and aponia (absence of pain) of the body in order to attain a blissful life (Epicurus, Letter to Menoeceus, 131). In this context, katastematic pleasure is, according to Epicurus, the ultimate purpose in life, and it is achieved through sober reasoning. It is sober reasoning, “... which decides every choice and avoidance and liberates us from the false beliefs which are the greatest source of anxiety" (Epicurus, Letter to Menoeceus, 132).

\section{Sober Reasoning, a philosophical cure against the politicization of medical truth?}

To summarise what we have discussed so far, we would argue that the shift established by Epicurus' ethics through the Tetrapharmakos constitutes a rupture with the traditional meaning of the word pharmakon insofar as it shows that by restoring the function of phronesis, sober reasoning is the ultimate end of a philosophical cure for the mind. According to Epicurus, because of its critique of misleading epistemological criteria of truth, phronesis is more valuable than even philosophy, since it is the natural source of all virtues, to the extent that it aims at cultivating life in accordance with katastematic pleasure, which, as we have seen, is a prerequisite for attaining a blissful life. From this point of view, we could argue that phronesis is a pharmakon against the purposive epistemological error used by Sophists in order to induce irrational fears to establish power and, thus, to make the pharmakon political liberation by 
exploiting situational fears. In concluding, we could claim that sober reasoning is shown to be the main means of transcending the human condition so that, as Epicurus characteristically states, "you shall live like a god among men..." (Epicurus, Letter to Menoeceus, 135). In that sense, establishing an enhancement of human nature as it ensues from the Epicurean ethics of the tetrapharmakos constitutes a critical philosophical paradigm against the politicization of medical truth.

\section{References}

Derrida, J. (1981). Dissemination (B. Johnson, Trans). University of Chicago Press.

Diogenes Laertius. The life of Epicurus. Attalus. http://www.attalus.org/old/diogenes10a.html Epicurus. Letter to Menoeceus. Epicurism. http://www.epicurism.info/etexts/Lives.html

Gaisford Th., (Ed.). (19672). Etymologicon Magnum. Amsterdam. (Original work published in 1848)

Nussbaum, M. (1994). The therapy of desire: Theory and practice in Hellenistic ethics. Princeton University Press. 